\title{
Comparison of three commercial serological tests for the detection of Chlamydia abortus infection in ewes
}

\author{
L. M. O’Neill ${ }^{*} \mathbb{B}$, Á. O’Driscoll ${ }^{\dagger}$ and B. Markey
}

\begin{abstract}
Background: 20.9\% of diagnosable abortions in Ireland in 2015 were caused by Chlamydia abortus infection. Abortion usually occurs in the last 2-3 weeks of gestation, and up to 30\% of ewes may be affected in naïve flocks. Serological diagnosis of EAE in flocks using LPS or whole bacteria as antigens is often hindered by cross reactions with C. pecorum. Although the complement fixation test is the official test for diagnosis of EAE, more sensitive and specific ELISA based tests have been developed. This study aimed to compare three commercial ELISA kits to detect $C$. abortus antibodies in ewes and to determine which of the kits had the highest sensitivity. The IDvet kit utilises a MOMP peptide antigen, the MVD-Enfer kit is based on a POMP90-3 antigen while the LSI kit plates are coated with chlamydial LPS. The study also aimed to examine the potential of these ELISAs to distinguish infected animals that go on to abort compared to those that have live lambs. Ewes were vaccinated with either a commercial live vaccine $(n=10)$ or Tris-buffer sham inoculation $(n=9) 5$ months prior to gestation, these ewes were then challenged with $C$. abortus $\left(1 \times 10^{6} \mathrm{IFU} / \mathrm{ml}\right)$ on day 90 of gestation. Sera were collected at prevaccination, 14 days post vaccination, 35 days post vaccination, pre-challenge, 35 days post challenge and 3 weeks post lambing/abortion ( $\sim 70$ days post challenge) and tested using the 3 aforementioned ELISAs to determine if one ELISA was more sensitive at detecting circulating anti-chlamydial antibodies.

Results: Sensitivity was highest with the LSI test kit at 94.74\%, followed by the MVD-Enfer and IDvet kits, at 78.95 and 73.68\% respectively. Ewes vaccinated with Enzovax became seropositive at 14 days post vaccination with all kits. Following challenge at day 90 of gestation, antibody titres steadily rose in all groups of ewes. With all ELISA kits, antibody levels were higher in ewes that aborted compared to ewes that had live lambs at 35 days post challenge and three weeks post lambing, and statistically significantly higher antibody levels were recorded in ewes that aborted compared to ewes that had live lambs using the MVD-ENFER ELISA at three weeks post lambing $(P=0.0482)$.

Conclusions: The LSI assay was the most sensitive out of the three kits tested in this study, when sera were tested at three weeks post lambing. As the LPS used in this kit is cross-reactive with all chlamydia, it is good for identifying flocks infected with any chlamydial species, but it is not considered specific for C. abortus. Furthermore, antibody levels were higher in ewes that aborted compared to ewes that had live lambs, at both 35 days post challenge and at three weeks post lambing. Future work should include evaluation of a larger number of sera at a wider range of time-points as well as an estimation of the specificity of commercially available assays.
\end{abstract}

Keywords: Chlamydia abortus, Enzootic abortion of ewes, ELISA sensitivity, ELISA comparison

\footnotetext{
* Correspondence: lauren.oneill@ucd.ie

${ }^{\dagger}$ L. M. O'Neill and Á. O'Driscoll contributed equally to this work.

School of Veterinary Medicine, University College Dublin, Room 07A, Belfield,

Dublin 4, Ireland
}

(c) The Author(s). 2018 Open Access This article is distributed under the terms of the Creative Commons Attribution 4.0 International License (http://creativecommons.org/licenses/by/4.0/), which permits unrestricted use, distribution, and reproduction in any medium, provided you give appropriate credit to the original author(s) and the source, provide a link to the Creative Commons license, and indicate if changes were made. The Creative Commons Public Domain Dedication waiver (http://creativecommons.org/publicdomain/zero/1.0/) applies to the data made available in this article, unless otherwise stated. 


\section{Background}

Enzootic abortion of ewes (EAE) is the second most common infectious cause of ovine abortion in Ireland, causing $20.9 \%$ of diagnosable abortions in 2015 [1]. The causative agent, Chlamydia abortus, is a serious zoonotic pathogen in pregnant women which makes accurate testing essential in the diagnosis and control of infected sheep [2]. The disease manifests itself as a placentitis, leading to abortion in the last 2 to 3 weeks of gestation [3]. Aborting ewes are the principal means of transmission of infection but rarely show prior clinical signs. As a result early, detection of infection during pregnancy is vital in permitting therapeutic intervention and controlling the spread of disease.

Serological diagnosis of EAE in flocks is challenging for a number of reasons. When serological tests such as the complement fixation test (CFT) use LPS or whole bacteria as antigens in the diagnosis of $C$. abortus infection, specificity tends to be low as cross reactions with Chlamydia pecorum are often observed [4]. Chlamydia pecorum mainly causes inapparent enteric infections [5], but is also known to cause arthritis, conjunctivitis and pneumonia [3]. Cross-reactive antibodies may arise from other chlamydial species and certain Gram-negative bacteria such as Acinetobacter spp. [4]. Thus, specific diagnostic tests are required to properly understand the epidemiology of EAE and in implementing control strategies. The diagnosis of EAE is further complicated by the ability of $C$. abortus to cause latent infections [6]. Pathological lesions in the ovine placenta do not usually develop until day 90 of gestation [7].

The CFT is the most widely used technique for serological diagnosis of EAE and is considered the gold standard test for official trade purposes [8]. However, advances have been made in the development of more sensitive and specific tests such as ELISAs that specifically detect antibodies to a range of chlamydial antigens including major outer membrane protein (MOMP) and polymorphic outer membrane proteins (POMP) [9].

The aim of this study was to compare three commercial ELISAs designed to detect antibodies to C. abortus in ewes. Each ELISA utilises a different chlamydial antigen. In the IDvet kit, wells are coated with a MOMP peptide antigen, which is known to have genus-, species, subspecies- and serotype-specific immunodomains [10]. Wells of the MVD-Enfer kit are coated with a POMP90-3 antigen considered to be specific for $C$. abortus [11]. The LSI kit uses chlamydial LPS as the antigen coating the wells. This is a genus-specific antigen common to all chlamydial species [12].

The study aimed to determine which of the three kits had the highest sensitivity and to evaluate the influence of the different antigens used in the assays on test characteristics. Furthermore, the study aimed to evaluate the potential of the different kits to identify ewes that subsequently progress to abortion.

\section{Method}

Sera from two groups of ewes $(n=19)$ were tested using three different commercial ELISA kits: IDvet, LSI and MVD-Enfer. The sera were generated as part of a vaccination trial [13]. This trial involved 5 different treatment groups including the testing of novel recombinant protein vaccines against EAE. The sera from the positive control ewes that received a live commercial vaccine and the negative control ewes that received a sham Tris-buffer inoculation were used in the current study. In summary, ten ewes were vaccinated 5 months prior to mating with Enzovax (MSD Animal Health), the commercial vaccine used in Ireland, while the nine were given a sham inoculation of Tris-buffer (control ewes). All the ewes were challenged by subcutaneous inoculation at day 90 of gestation with $10^{6}$ IFU of C. abortus isolate C95/27. All sera were tested at six time-points: $1=$ prevaccination, $2=14$ days post vaccination, $3=35$ days post vaccination, $4=$ pre-challenge, $5=35$ days post challenge and $6=$ three weeks post lambing. All sera were thawed at room temperature while the kit reagents were brought to room temperature. The ELISAs were carried out according to manufacturers' instructions. The format of each ELISA tested was an indirect ELISA. The S/P\% was calculated for each sample to determine the titres of antibodies using the formula $\left[\mathrm{OD}_{\text {sample }}-\mathrm{OD}\right.$ negative control $] /\left[\mathrm{OD}_{\text {positive }}\right.$ control- $\left.-\mathrm{OD}_{\text {negative control }}\right] \times 100$. For the LSI kit, a titre $>25$ $\mathrm{S} / \mathrm{P} \%$ was considered positive. For the IDvet kit, an S/P\% $\leq 50 \%$ was considered negative, an $\mathrm{S} / \mathrm{P} \%$ greater than $50 \%$ and less than $60 \%$ was considered doubtful and an S/ $\mathrm{P} \% \geq 60 \%$ was considered positive. For the MVD-Enfer kit, an $\mathrm{S} / \mathrm{P} \% \leq 20 \%$ was considered negative, an $\mathrm{S} / \mathrm{P} \%$ greater than $20 \%$ and less than $30 \%$ was considered doubtful and an $\mathrm{S} / \mathrm{P} \% \geq 30 \%$ was considered positive.

\section{Statistical analysis}

Statistical analysis of results was conducted on GraphPad Prism 7.03. Parametric unpaired t tests were carried out. Sensitivities (Se) of the kits were calculated using the results from three weeks post lambing and the following formula:

$$
\mathrm{Se}=\frac{\text { The number of diseased animals testing positive }}{\text { The total number of diseased animals }}
$$

The agreement between the ELISAs was determined from the Kappa coefficient ( $\mathrm{K}$ ) and percentage concordance for samples from all time points [14] using EpiTools epidemiological calculators [15]. Concordance was calculated as the sum of positive -positive values and negative-negative values expressed as a percentage of the total number of serum samples [16]. 


\section{Results}

All ELISA kits detected a similar trend in antibody levels post-vaccination and post-challenge. The antibody levels in the two groups of ewes at the six time-points are displayed in Figs. 1, 2, 3, 4, 5 and 6. The ewes vaccinated with the commercial vaccine showed a rise in antibody titre after vaccination (Figs. 1, 3 and 5). This is to be expected as it is a live vaccine and the animals were therefore exposed to the full range of chlamydial antigens. Antibody levels in both groups rose after challenge at day 90 of gestation (Figs. 1, 2, 3, 4, 5 and 6).

All ewes showed a steady rise in antibody levels after challenge, however the Enzovax vaccinated ewes at day 35 post challenge appeared to plateau (Figs. 1 and 3) unlike Tris-buffer vaccinated ewes (Figs. 2 and 4). It is important to note that in general the IDvet kit recorded higher antibody levels for both vaccine groups and peaked at levels higher than $150 \mathrm{~S} / \mathrm{P} \%$ (Fig. 3). The other ELISA kits did not exceed $150 \mathrm{~S} / \mathrm{P} \%$ (Figs. 1 and 5).

All Enzovax ewes after vaccination demonstrated a peak similar to that post-challenge, showing the difficulty of differentiating vaccinated ewes from infected ewes using the current commercial vaccine and available ELISAs.

The results of the MVD-Enfer kit for each individual Enzovax vaccinated ewe are detailed in Fig. 1. At day 14 post vaccination, four ewes tested negative and one ewe tested doubtful. Ewe number 3376 tested doubtful with an S/P\% of 26.69. Ewes 3543, 3554, 4773, 4901 all tested negative, with an $\mathrm{S} / \mathrm{P} \%$ of $6.39,2.56,12.23$ and 15.66 respectively. These five ewes all tested negative at day 35 post vaccination. Three ewes tested negative at both 35 days post challenge and 3 weeks post lambing, so antibody levels of these ewes did not show an increase following challenge. Ewes 3376, 3554 and 4901 had an $\mathrm{S} / \mathrm{P} \%$ of $1.18,1.34$ and 6.22 respectively, at 3 weeks post lambing. For the other ewes there was an increase in antibody levels after vaccination and again after challenge at day 90 of gestation.

The results of the MVD-Enfer kit for each individual Tris-buffer ewe are shown in Fig. 2. As expected, all ewes tested negative following the sham inoculation. At 35 days post challenge some ewes begin to test positive, with all ewes in the group testing positive at 3 weeks post-lambing. Ewe 3547 tested doubtful at 35 days post challenge with an $\mathrm{S} / \mathrm{P} \%$ of 24.48 , but this ewe subsequently tested positive at 3 weeks post lambing.

The antibody levels in individual ewes from the Enzovax group using the IDvet kit are shown in Fig. 3. In general, antibody levels rose following vaccination. However, four ewes did not test positive at either 14 or 35 days post vaccination. Ewe 3376 tested doubtful at day 14 with an $\mathrm{S} / \mathrm{P} \%$ of 51.17 and tested negative at day 35 with an $\mathrm{S} / \mathrm{P} \%$ of 25.19 . Ewe 3554 tested negative at day 14 and day 35 , with an S/P\% of 23.33 and 19.18 respectively. Ewe 4773 also tested negative at day 14 and day 35, with an $\mathrm{S} / \mathrm{P} \%$ of 49.81 and 25.21 respectively. Ewe 4901 tested doubtful at day 14 with an S/P\% of 56 . 90 and tested negative at day 35 with an S/P\% of 17.31 . Following challenge, there was a general rise in antibody levels, although four ewes did not fit this trend. At 3 weeks post lambing, ewe 3543 tested doubtful, with an S/P\% of 53.01. Furthermore, ewes 3554, 4749 and 4773 all tested negative at 3 weeks post lambing, with an S/P\% of $9.04,25.49$ and 8.29 respectively.

The results of the IDvet kit for Tris-buffer ewes are shown in Fig. 4. All ewes tested negative in the vaccine phase of the study. Most ewes in the group tested

\section{Enzovax ewes tested with MVD ENFER kit}

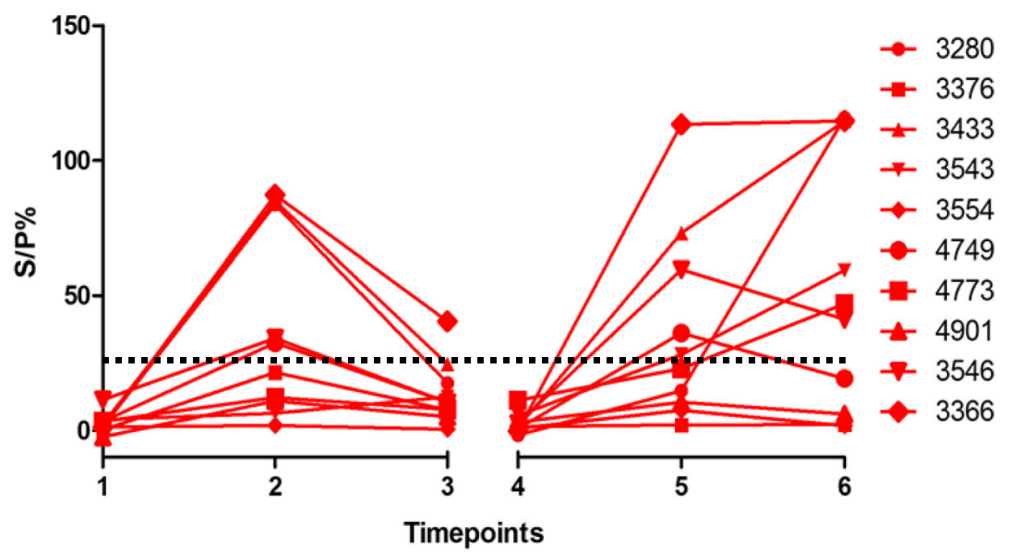

Fig. 1 Enzovax ewes tested with MVD-Enfer ki. MVD-Enfer kit showing antibody levels in ewes vaccinated with Enzovax across the six timepoints; $1=$ pre-vaccination, $2=14$ days post vaccination, $3=35$ days post vaccination, $4=$ pre-challenge, $5=35$ days post challenge and $6=3$ weeks post lambing. Ewes were vaccinated on day 0 and subsequently challenged at day 90 of gestation with $1 \times 10^{6} \mathrm{IFU}$ of C. abortus C95/27. Lambing occurred from day 125 of gestation until day 145 gestation. Dashed line indicates point of sero-positivity $>30$ S/P\% 


\section{Tris-buffer ewes tested with MVD ENFER kit}

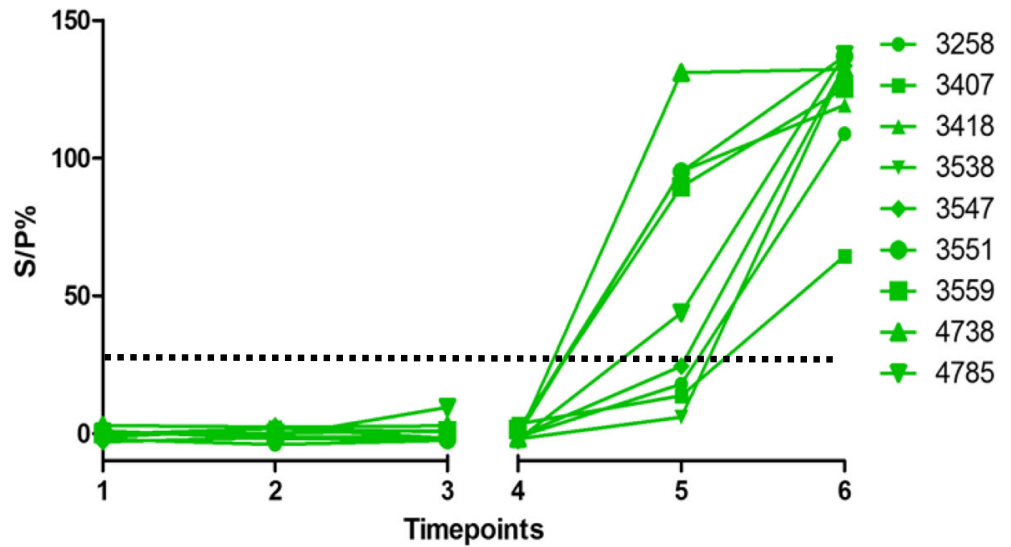

Fig. 2 Tris-buffer ewes tested with MVD-Enfer kit. MVD-Enfer kit showing antibody levels in ewes vaccinated with Tris-buffer across the six timepoints; as described in Fig. 1. Vaccination, challenge and lambing of ewes occurred as described in Fig. 1. Dashed line indicates point of sero-positivity > 30 S/P\%

positive at both 35 days post challenge and at 3 weeks post lambing. Ewe 3551 tested doubtful at 35 days post challenge with an $\mathrm{S} / \mathrm{P} \%$ of 56.09 , but subsequently tested positive at 3 weeks post lambing. However, ewe 3407 remained negative throughout the study; this ewe did not seroconvert at either 35 days post challenge or at 3 weeks post lambing. The $\mathrm{S} / \mathrm{P} \%$ was 4.55 and 5.10 at these time-points respectively.

The individual antibody levels for the Enzovax ewes recorded using the LSI kit are shown in Fig. 5. In general, antibody levels increased after vaccination. However, three ewes in this group tested negative at both 14 and 35 days post vaccination. Ewes 4749, 4773 and 4901 tested negative at day 14 post vaccination, with an $\mathrm{S} / \mathrm{P} \%$ of $19.43,14.62$ and 3.79 respectively. These ewes also tested negative at 35 days post vaccination, with an $\mathrm{S} / \mathrm{P} \%$ of $0.93,5.20$ and -13.73 respectively. As regards the challenge period, there was a general trend of rising antibody levels following inoculation. One ewe, 4773, tested negative at 3 weeks post lambing with an $\mathrm{S} / \mathrm{P} \%$ of 21.88 , but this ewe had tested positive previously at 35 days post challenge.

Results for the Tris-buffer ewes using the LSI kit are shown in Fig. 6. All ewes tested negative in the vaccine phase. Pre-challenge, all ewes in the group tested negative apart from two ewes, 3547 and 3559. These ewes had an $\mathrm{S} / \mathrm{P} \%$ of 36.56 and 46.41 respectively. At 35 days post challenge, all ewes tested positive apart from one

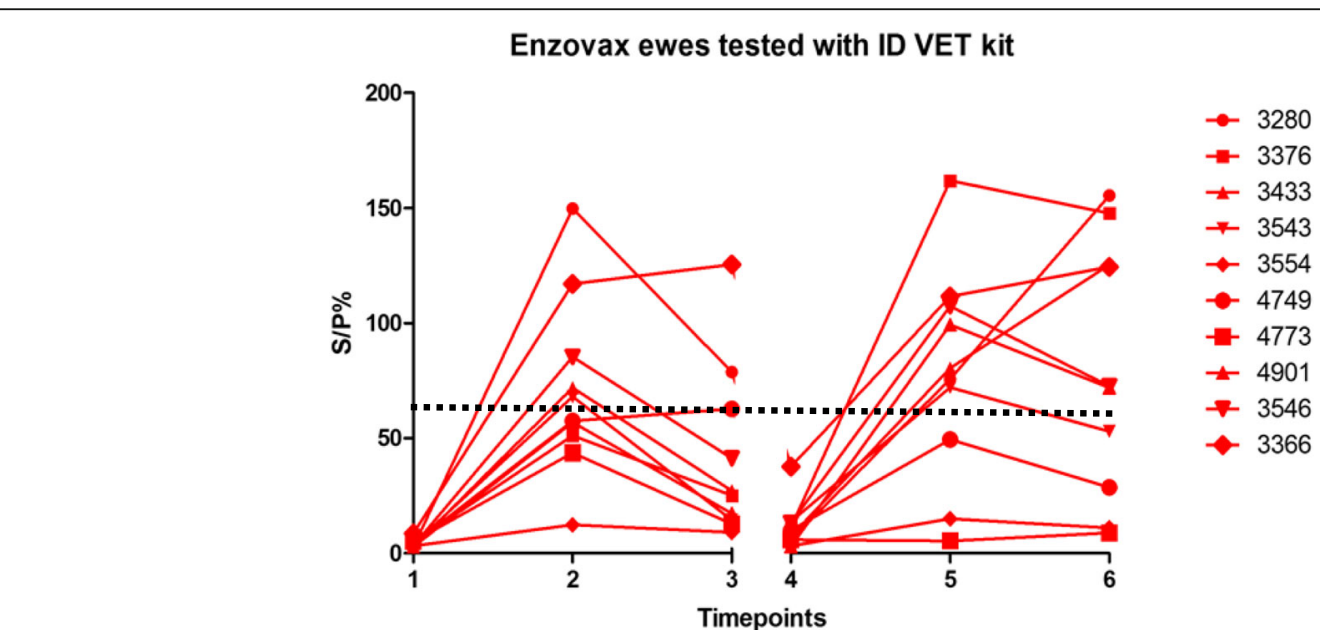

Fig. 3 Enzovax ewes tested with IDvet kit. IDvet kit showing antibody levels in ewes vaccinated with Enzovax across the six timepoints; as described in Fig. 1. Vaccination, challenge and lambing of ewes occurred as described in Fig. 1. Dashed line indicates point of sero-positivity $>60 \mathrm{~S} / \mathrm{P} \%$ 


\section{Tris-buffer ewes tested with ID VET kit}

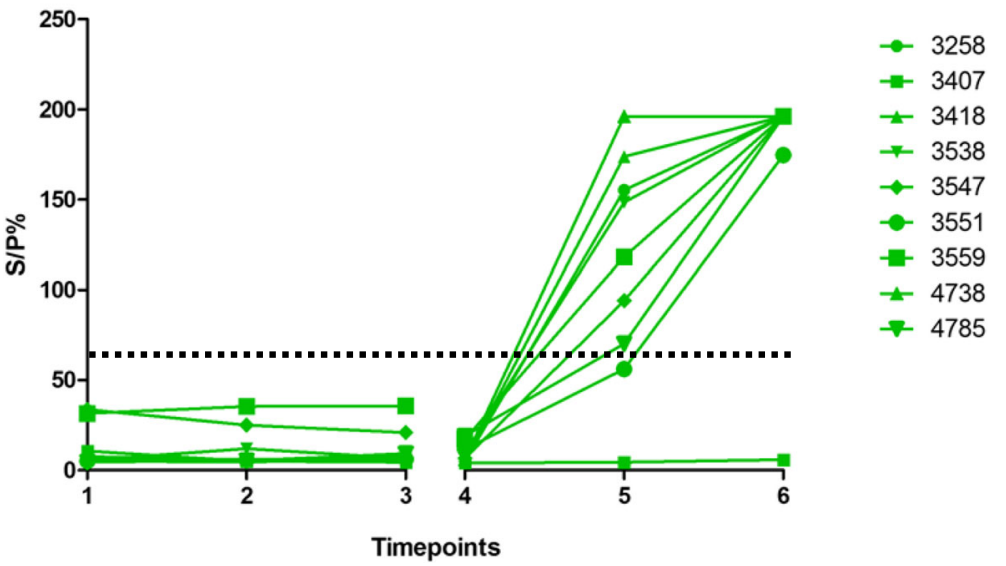

Fig. 4 Tris-buffer ewes tested with IDvet kit. IDvet kit showing antibody levels in ewes vaccinated with Tris-buffer across the six timepoints; as described in Fig. 1. Vaccination, challenge and lambing of ewes occurred as described in Fig. 1. Dashed line indicates point of sero-positivity > 60 S/P\%

ewe, 3538, which tested negative with an $\mathrm{S} / \mathrm{P} \%$ of 13.40 . This ewe did test positive at 3 weeks post lambing, as did all other ewes in the group.

In an effort to determine if there was a correlation between antibody levels and whether or not a ewe would abort, graphs were constructed to examine the levels of antibodies recorded from each ELISA in ewes that aborted compared to ewes that had live lambs. All ten Enzovax vaccinated ewes had live lambs while only three out of the nine Tris-buffer control ewes had live lambs (3258, 3547 and 4785). As shown in Fig. 7, antibody levels were higher at day 35 post challenge in ewes that went on to abort compared to ewes that produced live lambs for all kits. Furthermore, antibody levels were higher again at 3 weeks post lambing than at 35 days post challenge in both ewes that aborted and ewes that had live lambs. The MVD-Enfer kit detected a statistically significant difference between antibody levels in ewes at 3 weeks post lambing that had live or dead lambs $(P$ value $=0.0482)$. Statistically significant results were obtained with all kits with higher antibody levels at 3 weeks post lambing compared to 35 days post challenge for Tris-buffer control ewes (IDvet $P=0.0062$, MVD-Enfer $P=0.0021$, LSI $P=0.0222$ ).

The sensitivity of each ELISA kit was calculated according to the Se equation described previously. The IDvet kit had a sensitivity of $73.68 \%$ and the MVD-Enfer kit had a sensitivity of $78.95 \%$. The LSI kit had the highest sensitivity, at $94.74 \%$. The kappa coefficients demonstrated that all ELISAs had a "moderate to substantial"

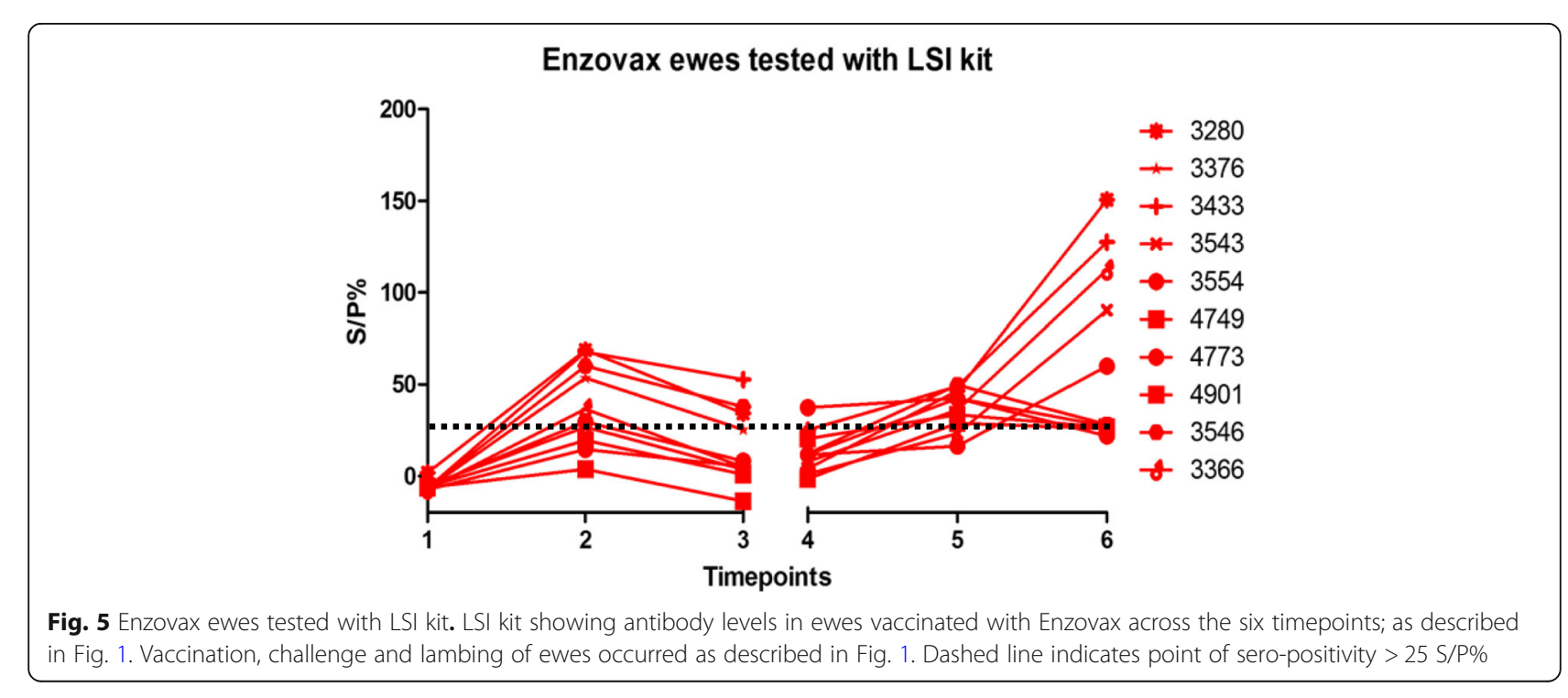




\section{Tris-buffer ewes tested with LSI kit}

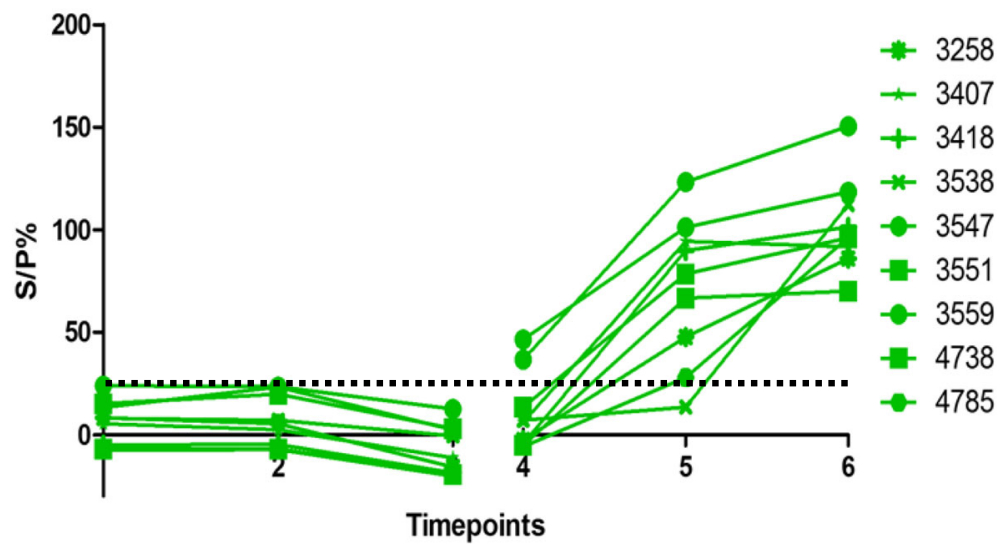

Fig. 6 Tris-buffer ewes tested with LSI kit. LSI kit showing antibody levels in ewes vaccinated with Tris-buffer across the six timepoints; as described in Fig. 1. Vaccination, challenge and lambing of ewes occurred as described in Fig. 1. Dashed line indicates point of

sero-positivity $>25 \mathrm{~S} / \mathrm{P} \%$

agreement [14] with kappa values ranging from 0.59-0. 70 when calculated using sera from all time points. Moderate agreement ranges from $0.41-0.60$ while substantial agreement ranges from 0.61-0.80 [14]. The percentage concordance between all three ELISAs was greater than $78 \%$ as shown in Table 1.

\section{Discussion}

Various studies have been conducted to date evaluating the sensitivity and specificity of ELISAs compared to CFT in the diagnosis of $C$. abortus infection $[9,11,17-20]$. The results of these studies vary, with McCauley et al. [18] describing equal sensitivities and specificities between CFT and the ELISAs tested. In contrast, Longbottom et al. [11] and Markey et al. [20] reported that ELISAs are a more sensitive serological test than CFT. As knowledge of the outer membrane proteins of C. abortus has increased over time, new antigenic proteins have been explored and have resulted in the creation of novel ELISA plates $[4,11]$.

The aim of this current study was to compare three commercial ELISAs coated with three different antigens; MOMP, POMP and LPS. All ELISAs demonstrated a "moderate to substantial" agreement $(0.59-0.70)$ [14] using the kappa coefficient test while the percentage of concordance was also greater than $78 \%$ in comparing all three ELISAs [16]. The LSI ELISA coated with

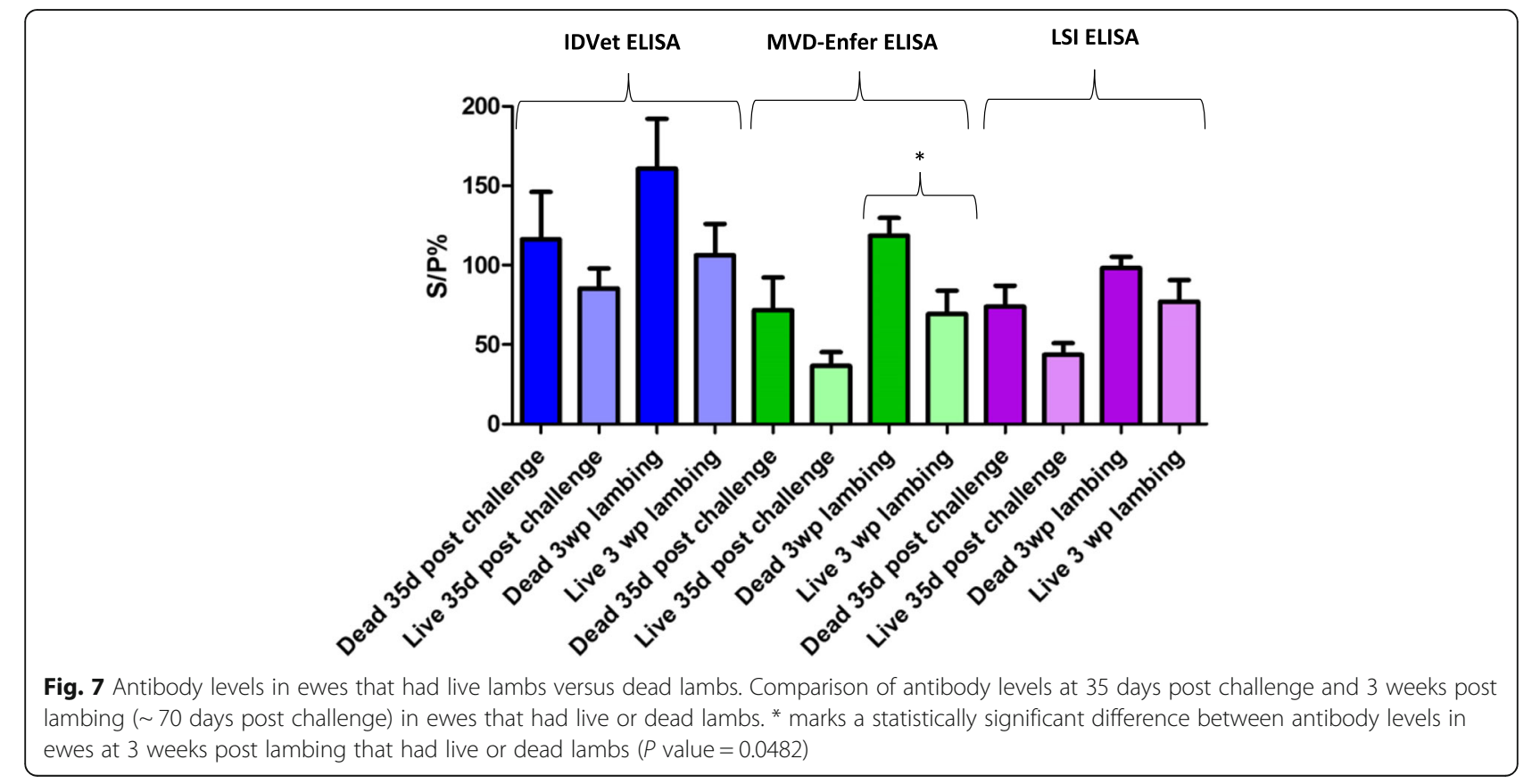


Table 1 Kappa coefficient values and concordance percentages for comparing the LSI kit to MVD kits, LSI kit to ID vet kit and ID vet kit to MVD kit using all data from the 6 time points; prevaccination, 14 days post vaccination, 35 days post vaccination, pre-challenge, 35 days post challenge and 3 weeks post lambing

\begin{tabular}{lll}
\hline & MVD ELISA & ID VET \\
\hline LSI ELISA & Kappa $(\mathrm{K})=0.5887 \%$ & Kappa $(\mathrm{K})=0.6842 \%$ \\
& concordance $=78.9$ & concordance $=80.7$ \\
MVD ELISA & & Kappa $(\mathrm{K})=0.7012 \%$ \\
& & concordance $=80.7$ \\
\hline
\end{tabular}

chlamydial LPS was the most sensitive at $94.74 \%$, when calculated at 3 weeks post lambing. This indicates that the LSI kit found more animals to be positive than the other kits and appears to be most effective in diagnosing the infection in individual animals. As well as sensitivity, specificity rates are essential data in determining the most effective serological test. Buendía et al. [21] suggested that mixed infections of $C$. abortus and $C$. pecorum are common in flocks. However, the specificities of these ELISAs were not calculated in this study as sera from ewes known to be infected with other chlamydial species such as C. pecorum were not available.

Another limitation of this study was that the small sample size with only 19 ewes included in the study. A larger sample size would be beneficial in evaluating these ELISAs and determining their sensitivities. Field sera from sheep naturally infected with $C$. abortus as well as sera from sheep known to be positive for $C$. pecorum would have been useful in evaluating these ELISAs. This would also have allowed specificity data to be calculated.

With the IDvet and MVD-Enfer kits in particular, a number of samples had to be retested as unexpected results were obtained the first time they were tested. As mentioned in the results, some ewes in the Enzovax group did not test positive at any time-point with the MVD-Enfer kit, even after retesting. This was an interesting finding and warrants further investigation.

With the IDvet kit two Enzovax ewes remained negative after vaccination and challenge, even after the samples were retested. These examples of sera that required retesting show that the accuracy of these tests must be taken into consideration and demonstrates that the results were sometimes difficult to interpret. The LSI kit therefore seemed to be the most effective kit in this study but a greater number of samples would need to be tested across more time-points to confirm this. One possible option would be to screen flocks with the LSI kit to identify all ewes infected with Chlamydia species and then to use the other kits to detect ewes infected with $C$. abortus only. However, this approach may not be economically feasible.
Although an LPS-based ELISA fails to distinguish between $C$. abortus and C. pecorum infected ewes, Griffiths et al. [22] suggest it is a more sensitive screening test than the CFT, especially in flocks where abortion has occurred. Kaltenboeck et al. [23] also showed that a chlamydial LPS ELISA was more sensitive than the CFT and may be a suitable replacement. Furthermore, a purified LPS-based ELISA prepared by Sting and Hafez [24] was shown to be more sensitive than the CFT.

As regards MOMP-based ELISAs, much of the literature has examined their sensitivities in comparison to the CFT [4, 18, 25, 26]. A competitive ELISA described by Salti-Montesanto et al. [25] diagnosed 9 out of 10 infected flocks whereas the CFT detected only 6 out of 10 infected flocks in the study. Hoelzle et al. [26] suggested that recombinant MOMP antigens are suitable for use in serological tests and may eliminate binding of crossreactive antibodies. While McCauley et al. [18] reported a sensitivity of $70.4 \%$ when using MOMP synthetic peptide-based ELISA, other literature suggests that a MOMP ELISA based on the variable segment 2 region yields similar results to the CFT, lacks sensitivity and is therefore not suitable for use as a screening test [4].

Numerous studies have investigated the use of POMP antigens in serological assays for the detection of $C$. abortus antibodies [9, 11, 19, 21, 27]. Buendía et al. [21] reported a sensitivity of $90.9 \%$ when using an $80-90 \mathrm{kDa}$ POMP-based ELISA in comparison to the CFT which was $71 \%$ sensitive, while also offering the possibility of differentiating rMOMP-vaccinated ewes from naturally infected ewes. In another study investigating a recombinant POMP80-90 ELISA a sensitivity of $80 \%$ was calculated, which was higher in comparison to the CFT [19]. However, when using field sera, a lower sensitivity was obtained [19]. Longbottom et al. [27] described an indirect ELISA created using a recombinant POMP91B fragment which yielded a sensitivity of $84.2 \%$, which was greater than that of the CFT. The ELISA also proved more effective at distinguishing between $C$. abortus and C. pecorum infections [27]. A further study was carried out based on a recombinant POMP90 ELISA [11]. Both the rOMP90-3 and rOMP90-4 ELISAs had higher sensitivities than the CFT, with the rOMP90-4 fragment being more sensitive than the rOMP90-3 fragment when testing field sera [11]. In contrast, Wilson et al. [9] reported the rOMP90-3 ELISA as being more sensitive than both the CFT and the rOMP90-4 ELISA, with results of 96.8, 93.5 and $91.9 \%$ respectively. A sensitivity of 96.8\% with the rOMP90-3 ELISA [9] is higher than the result of $78.95 \%$ obtained in the current study.

Interestingly anti-chlamydial antibody levels were found to be consistently higher after challenge in ewes that aborted compared to ewes that had live lambs. Studies have shown increases in antibody levels associated with $C$. 
abortus reproductive failure [28-30]. Gutierrez et al. [31] and García-Seco et al. [32] have also noted that antibody titres were lower in animals that did not go on to abort. This current study and others clearly show how elevated antibody levels could form a basis to identify ewes that will go on to abort. The antibody increase observed in all groups at 3 weeks post lambing could be associated with the development of protective immunity against subsequent abortions as described by García-Seco et al. [32] and Longbottom and Coulter [33]. Alternatively it may simply be a diagnostic marker of exposure to high numbers of circulating C. abortus. In any case early warning of impending abortions could have significant benefits in terms of targeting long- acting antimicrobial treatment [3] towards those animals in imminent danger of abortion rather than having to administer treatment to the whole flock.

It is clear from the literature available that a lot of variation exists in the sensitivities of different ELISAs. In general, ELISAs have been shown to be more sensitive than CFT, in particular the POMP ELISAs as described above. Hagemann et al. [34] described how antibodies to virulence-associated antigens such as chlamydial proteaselike activity factor (CPAF) are not present for more than 18 weeks after abortion in most cases, whereas antibodies to surface antigens such as MOMP persist for longer. However, in ewes that lamb normally, antibodies to surface antigens do not persist [34]. It has also been shown by Livingstone et al. [4] that anti-MOMP antibodies only increase around the time of abortion and then gradually decline, while anti-POMP antibodies appear earlier and may persist for longer. It is therefore evident that differences in immunoreactivites may be due to the time-points at which blood samples are taken following abortion, as described by Forsbach-birk et al. [35]. It is important to note that the current study was limited to six specific time-points and therefore the peak level of antibody, after abortion may have been missed. Future work would be valuable in assessing these ELISAs using sera from different time-points, for example at various points throughout gestation and beyond 3 weeks post lambing.

\section{Conclusions}

This study demonstrated that when sera are tested at 3 weeks post lambing the LSI kit was the most sensitive of the three commercial kits examined. As the LPS used in the LSI kit is cross-reactive with all chlamydia, it is suited to identifying flocks infected with any chlamydial species. It is clear from the data presented that ewes vaccinated with Enzovax usually become seropositive at 14 days after vaccination. This study also showed that antibody levels are higher in ewes that abort compared to ewes that have live lambs. In both ewes that aborted and ewes that have live lambs, antibody levels were higher at 3 weeks post lambing than at 35 days post challenge. Future work involving more sera, as well as testing at more time-points, would be beneficial in confirming the results obtained in this study.

\section{Acknowledgements \\ The authors gratefully acknowledge the support of the Thomas O'Hanlon Bursary for AOD. Additionally the authors gratefully acknowledge the research support of Teagasc, UCD and DAFM.}

\section{Funding}

The authors gratefully acknowledge the funding support for the project from the Thomas O'Hanlon Bursary for AOD and from the School of Veterinary Medicine, UCD for laboratory consumables. Additionally the authors gratefully acknowledge the funding support of Teagasc for LMON and of the Department of Agriculture, Food and the Marine (DAFM) in carrying out the experimental trial.

\section{Availability of data and materials}

The data sets used and analysed during the current study are available from the corresponding author on reasonable request.

\section{Authors' contributions}

LMON and BM collected the serum for this study. AOD and LMON ran the ELISAs and analysed the resulting data. LMON, AOD and BM contributed in writing this manuscript. All authors read and approved the final manuscript.

Ethics approval and consent to participate

Ethical approval was granted by the Animal Research Ethics Committee (AREC) at University College Dublin (UCD) under license AREC-14-10 Markey and all procedures were performed under experimental license from the Health Products Regulatory Authority (HPRA) for Ireland under license AE 19113/P004

\section{Competing interests}

The authors declare that they have no competing interests.

\section{Publisher's Note}

Springer Nature remains neutral with regard to jurisdictional claims in published maps and institutional affiliations.

Received: 13 October 2017 Accepted: 10 May 2018

Published online: 29 May 2018

References

1. All-Island Animal Disease Surveillance Report 2015 https://www.agriculture. gov.ie/media/migration/animalhealthwelfare/labservice/rvlreports/2016/ 2015AFBIDAFMAlllslandSurveillanceReport190117.pdf.

2. Wong S, Gray E, Buxton D, Finlayson J, Johnson F. Acute placentitis and spontaneous abortion caused by Chlamydia psittaci of sheep origin: a histological and ultrastructural study. J Clin Pathol. 1985:38(6):707-11.

3. Aitken I, Longbottom D. Chlamydial abortion. In: Diseases of sheep. 4th ed. Oxford: Blackwell Science; 2007. p. 105-12.

4. Livingstone M, Entrican G, Wattegedera S, Buxton D, McKendrick I, Longbottom $\mathrm{D}$. Antibody responses to recombinant protein fragments of the major outer membrane protein and polymorphic outer membrane protein POMP90 in Chlamydophila abortus-infected pregnant sheep. Clin Vaccine Immunol. 2005:12(6):770-7.

5. Berri M, Rekiki A, Boumedine K, Rodolakis A. Simultaneous differential detection of Chlamydophila abortus, Chlamydophila pecorum and Coxiella burnetii from aborted ruminant's clinical samples using multiplex PCR. BMC Microbiol. 2009:9(1):130.

6. Rocchi M, Wattegedera S, Meridiani I, Entrican G. Protective adaptive immunity to Chlamydophila abortus infection and control of ovine enzootic abortion (OEA). Vet Microbiol. 2009:135(1-2):112-21.

7. Buxton D, Barlow R, Finlayson J, Anderson I, Mackellar A. Observations on the pathogenesis of Chlamydia psittaci infection of pregnant sheep. J Comp Pathol. 1990;102(2):222-37.

8. Aitken ID, Longbottom D. Enzootic abortion of ewes (ovine chlamydiosis). In: OIE Biological Standards Commission, Manual of Diagnostic Tests and 
Vaccines for Terrestrial Animals (Mammals, Birds and Bees). 7th ed. Paris: Office International des Epizooties; 2012.

9. Wilson K, Livingstone M, Longbottom D. Comparative evaluation of eight serological assays for diagnosing Chlamydophila abortus infection in sheep. Vet Microbiol. 2008;135(1-2):38-45.

10. Conlan J, Clarke I, Ward M. Epitope mapping with solid-phase peptides: identification of type-, subspecies-, species- and genus-reactive antibody binding domains on the major outer membrane protein of Chlamydia trachomatis. Mol Microbiol. 1988;2(5):673-9.

11. Longbottom D, Fairley S, Chapman S, Psarrou E, Vretou E, Livingstone M. Serological diagnosis of ovine enzootic abortion by enzyme-linked immunosorbent assay with a recombinant protein fragment of the polymorphic outer membrane protein POMP90 of Chlamydophila abortus. J Clin Microbiol. 2002;40(11):4235-43.

12. Brade H, Brade L, Nano F. Chemical and serological investigations on the genus-specific lipopolysaccharide epitope of Chlamydia. Proc Natl Acad Sci. 1987:84(8):2508-12.

13. O'Neill LM. Evaluation of recombinant MIP and CPAF from Chlamydia abortus as novel vaccines for Enzootic Abortion of Ewes. PhD Thesis, UCD 2017.

14. McHugh ML. Interrater reliability: the kappa statistic. Biochemia medica: Biochemia medica. 2012;22(3):276-82

15. Sergeant, ESG, 2018. Epitools epidemiological calculators. Ausvet Pty Ltd. Available at: http://epitools.ausvet.com.au. Accessed 28 Feb 2018.

16. Wilson K, Livingstone M, Longbottom D. Comparative evaluation of eight serological assays for diagnosing Chlamydophila abortus infection in sheep. Vet Microbiol. 2009;135(1-2):38-45.

17. Jones G, Low J, Machell J, Armstrong K. Comparison of five tests for the detection of antibodies against chlamydial (enzootic) abortion of ewes. Vet Rec. 1997;141(7):164-8.

18. McCauley L, Lancaster M, Young P, Butler K, Ainsworth C. Comparison of ELISA and CFT assays for Chlamydophila abortus antibodies in ovine sera. Aust Vet J. 2007;85(8):325-8.

19. Vretou E, Radouani F, Psarrou E, Kritikos I, Xylouri E, Mangana O. Evaluation of two commercial assays for the detection of Chlamydophila abortus antibodies. Vet Microbiol. 2007;123(1-3):153-61.

20. Markey B, McNulty M, Todd D. Comparison of serological tests for the diagnosis of Chlamydia psittaci infection of sheep. Vet Microbiol. 1993; 36(3-4):233-52.

21. Buendía A, Cuello F, Del Rio L, Gallego M, Caro M, Salinas J. Field evaluation of a new commercially available ELISA based on a recombinant antigen for diagnosing Chlamydophila abortus (Chlamydia psittaci serotype 1) infection. Vet Microbiol. 2001;78(3):229-39.

22. Griffiths $\mathrm{PC}$, Plater JM, Horigan MW, Rose MP, Venables C, Dawson M. Serological diagnosis of ovine enzootic abortion by comparative inclusion immunofluorescence assay, recombinant lipopolysaccharide enzyme-linked immunosorbent assay, and complement fixation test. J Clin Microbiol. 1996; 34(6):1512-8.

23. Kaltenboeck B, Heard D, DeGraves FJ, Schmeer N. Use of synthetic antigens improves detection by enzyme-linked immunosorbent assay of antibodies against abortigenic Chlamydia psittaci in ruminants. J Clin Microbiol. 1997; 35(9):2293-8.

24. Sting R, Hafez H. Purification of Chlamydia psittaci antigen by affinity chromatography on polymyxin B agarose for use in the enzymelinked immunosorbent assay (ELISA). Zentralblatt für Bakteriologie. 1992;277(4):436-45

25. Salti-Montesanto V, Tsoli E, Papavassiliou P, Psarrou E, Markey BK, Jones GE, Vretou E. Diagnosis of ovine enzootic abortion, using a competitive ELISA based on monoclonal antibodies against variable segments 1 and 2 of the major outer membrane protein of Chlamydia psittaci serotype 1. Am J Vet Res. 1997;58(3):228-35.

26. Hoelzle L, Hoelzle K, Wittenbrink M. Recombinant major outer membrane protein (MOMP) of Chlamydophila abortus, Chlamydophila pecorum and Chlamydia suis as antigens to distinguish chlamydial species-specific antibodies in animal sera. Vet Microbiol. 2004;103(1-2):85-90.

27. Longbottom D, Psarrou E, Livingstone M, Vretou E. Diagnosis of ovine enzootic abortion using an indirect ELISA (rOMP91B BELISA) based on a recombinant protein fragment of the polymorphic outer membrane protein POMP91B of Chlamydophila abortus. FEMS Microbiol Lett. 2001;195(2):157-61.

28. Wilsmore A, Wilsmore B, Dagnall G, Izzard K, Woodland R, Dawson M, Venables C. Clinical and immunological responses of ewes following vaccination with an experimental formalin-inactivated Chlamydia psittaci (ovis) vaccine and subsequent challenge with the live organism during pregnancy. Br Vet J. 1990;146(4):341-8.

29. Navarro J, García de la Fuente J, Sánchez J, Martínez C, Buendía A, GutiérrezMartín C, Rodriguez-Ferri E, Ortega N, Salinas J. Kinetics of infection and effects on the placenta of Clamydophila abortus in experimentally infected pregnant ewes. Vet Pathol. 2004;41(5):498-505.

30. Papp JR, Shewen PE, Gartley CJ. Abortion and subsequent excretion of chlamydiae from the reproductive tract of sheep during estrus. Infect Immun. 1994;62(9):3786-92.

31. Gutierrez J, Williams E, O'Donovan J, Brady C, Proctor A, Marques P, Worrall S, Nally J, McElroy M, Bassett H, Sammin D, Markey B. Monitoring clinical outcomes, pathological changes and shedding of Chlamydophila abortus following experimental challenge of periparturient ewes utilizing the natural route of infection. Vet Microbiol. 2011;147(1-2):119-26.

32. García-Seco T, Pérez-Sancho M, Salinas J, Navarro A, Díez-Guerrier A, García N, Pozo P, Goyache J, Domínguez L, Álvarez J. Effect of preventive Chlamydia abortus vaccination in offspring development in sheep challenged experimentally. Front Vet Sci. 2016;3:67.

33. Longbottom D, Coulter L. Animal Chlamydioses and zoonotic implications. J Comp Pathol. 2003;128(4):217-44.

34. Hagemann J, Simnacher U, Longbottom D, Livingstone M, Maile J, Soutschek E, Walder G, Boden K, Sachse K, Essig A. Analysis of humoral immune responses to surface and virulence-associated Chlamydia abortus proteins in ovine and human abortions by use of a newly developed line immunoassay. J Clin Microbiol. 2016;54(7):1883-90.

35. Forsbach-birk V, Foddis C, Simnacher U, Wilkat M, Longbottom D, Walder G, Benesch C, Ganter M, Sachse K, Essig A. Profiling antibody responses to infections by Chlamydia abortus enables identification of potential virulence factors and candidates for Serodiagnosis. PLoS One. 2013;8(11):80310.

\section{Ready to submit your research? Choose BMC and benefit from:}

- fast, convenient online submission

- thorough peer review by experienced researchers in your field

- rapid publication on acceptance

- support for research data, including large and complex data types

- gold Open Access which fosters wider collaboration and increased citations

- maximum visibility for your research: over $100 \mathrm{M}$ website views per year

At BMC, research is always in progress.

Learn more biomedcentral.com/submissions 